\title{
MANEJOS DE NITROGÊNIO E DO LODO DE ESGOTO NA CULTURA DO TRIGO
}

\author{
Thomaz Figueiredo Lobo ${ }^{1}$, Helio Grassi Filho ${ }^{2}$, Leonardo Theodoro Bull ${ }^{2}$, Flavia Luize Pereira de Souza ${ }^{1}$ \\ ${ }^{1}$ Universidade Sagrado Coração - USC, Curso de Engenharia Agronômica, Bauru, SP. ${ }^{2}$ Universidade Estadual Paulista - \\ UNESP, Faculdade de Ciências Agronômicas, Departamento de Recursos Naturais e Ciencia do Solo, Botucatu , SP. E- \\ mail: thomaz.lobo@superig.com.br
}

\section{RESUMO}

A disposição final do lodo de esgoto vem se caracterizando como um dos problemas ambientais urbanos mais relevantes da atualidade. Geralmente este resíduo é encaminhado para o aterro sanitário e o processo de descarte tem custo elevado. $O$ objetivo deste trabalho foi verificar o efeito do nitrogênio e do lodo de esgoto compostado nos parâmetros produtivos do trigo. 0 experimento tem histórico de 6 cultivos mantidos os mesmos tratamentos. O experimento foi conduzido na Fazenda Experimental São Manuel, pertencente à Faculdade de Ciências Agronômicas da UNESP de Botucatu. Foi adotado o delineamento experimental em blocos casualizados, constituídos por 6 tratamentos e 5 repetições assim definidos: T0 sem adubação nitrogenada; T1 - adubação mineral nitrogenada de acordo com a necessidade da cultura; T2 - 50\% da adubação nitrogenada proveniente do lodo de esgoto e 50\% na forma mineral; T3 - 100\% da adubação nitrogenada proveniente do lodo de esgoto; T4 - 150\% da adubação nitrogenada proveniente do lodo de esgoto; T5 - 200\% da adubação nitrogenada proveniente do lodo de esgoto. 0 tratamento que proporcionou uma maior produtividade de grão e matéria seca foi o tratamento que recebeu a maior dose de lodo.

Palavras-chave: adubação orgânica; rendimento; sustentabilidade.

\section{MANAGEMENT OF NITROGEN AND SEWAGE SLUDGE IN WHEAT CROP}

\begin{abstract}
The final disposal of sewage sludge is one of the most relevant urban environmental problems nowadays. Presently this waste is sent to the landfill and the disposal process has a high cost. The objective of this work is to verify the effect of nitrogen and composted sewage sludge on wheat production parameters. The experiment has a history of 6 cultures with the same treatments. The experiment was conducted at the São Manuel Experimental Farm, belonging to the Faculty of Agronomic Sciences of UNESP of Botucatu. A randomized complete block design was used, consisting of 6 treatments and 5 replicates: T0 - without nitrogen fertilization; T1 - nitrogenous mineral fertilization according to the need of the crop; T2 - 50\% of the nitrogen fertilization from the sewage sludge and $50 \%$ in the mineral form; $\mathrm{T} 3-100 \%$ of the nitrogen fertilization from the sewage sludge; T4 - 150\% of nitrogen fertilization from sewage sludge; T5 - 200\% of nitrogen fertilization from sewage sludge. The treatment that provided a higher productivity of grain and dry matter was the treatment that received the highest dose of sludge.
\end{abstract}

Keywords: organic fertilization; yield; sustainability.

\section{INTRODUÇÃO}

A disposição final do lodo de esgoto vem se caracterizando como um dos problemas ambientais urbanos mais relevantes da atualidade, e que cresce diariamente tanto nos países desenvolvidos quanto naqueles em desenvolvimento, como reflexo da ampliação das redes de coleta e incremento dos níveis de tratamento (PEGORINI et al., 2003). O esgoto urbano, quando submetido a tratamento adequado, gera o chamado "lodo de esgoto" e, depois de passar por desinfecção, pode ser disponibilizado para a utilização agrícola (CHUEIRI et al., 2007). 
No Brasil, a disposição final do lodo geralmente é o aterro sanitário. Além do alto custo, que pode chegar a $50 \%$ do custo operacional de uma Estação de Tratamento de Esgoto (ETE) disposição do resíduo com elevada carga orgânica no aterro agrava ainda mais o problema com o manejo do lixo urbano (BETIOL; CAMARGO, 2007).

A utilização de lodo de esgoto é uma prática altamente promissora para $\mathrm{O}$ desenvolvimento de sistemas agrícolas sustentáveis. Porem existem normas rígidas que devem levar em consideração para elaboração de projetos para minimizar o impacto negativo desta prática ao ambiente, esta norma técnica é a P4.240 (CONAMA, 2006).

Diversos trabalhos demonstram aumentos na produção de matéria seca e de grãos por espécies de interesse agronômico cultivadas em solos tratados com lodo de esgoto (LOBO et al., 2012; DEFELIPO et al., 1991).

O N contido no lodo de esgoto poderá restringir a taxa de aplicação mais do que os teores de metais pesado, devido à mineralização de sua carga orgânica e subsequente lixiviação de nitrato $\left(\mathrm{NO}_{3}{ }^{-}\right)$(OLIVEIRA, 2000), quando em doses acima de $50 \mathrm{t} \mathrm{ha}^{-1} \mathrm{ano}^{-1}$, ou equivalente em N, acima de $300 \mathrm{~kg} \mathrm{ha}^{-1} \mathrm{ano}^{-1}$. A maioria dos nutrientes do lodo está na forma orgânica, como é destacado por Munhoz (2001), sendo que apenas cerca de 30 a $50 \%$ do $\mathrm{N}$ total está na forma prontamente aproveitável pelas plantas no primeiro ano (CONAMA, 2006).

Quando aplicado em taxas agronômicas, os lodos de esgoto podem reduzir em muito o custo de produção, pela menor utilização de fertilizantes minerais solúveis. No Colorado (EUA), a constante aplicação de $7,5 \mathrm{t} \mathrm{ha}^{-1}$ de lodo de esgoto a cada dois anos resultou em produção de trigo comparável com aplicação de 55-65 kg $\mathrm{ha}^{-1}$ de $\mathrm{N}$ na forma de fertilizante nitrogenado comercial. Na região metropolitana de São Paulo, estima-se uma produção de aproximadamente $500 \mathrm{t}$ de lodo de esgoto seco por dia. Considerando-se $3 \%$ de $\mathrm{N}$ orgânico, em média, e taxa de mineralização de $20 \%$ ao ano, somente os lodos de esgoto da região metropolitana de São Paulo poderiam suprir $3 \mathrm{t}$ de $\mathrm{N}$ por dia (LAMBAIS; SOUZA, 1999).

Para obter rendimentos elevados de trigo, é necessário aplicar fertilizantes nitrogenados, pois os solos, em geral, não suprem a demanda da cultura em $\mathrm{N}$ nos diversos estágios de desenvolvimento da planta este nutriente apresenta influencia no número de espigas por hectare, número de grãos por espiga e peso do grão (FORNASIERI, 2008).

Sabey et al. (1977) verificaram maior eficiência no desenvolvimento de plantas de trigo cultivado em solos que receberam lodo de esgoto, misturando com restos de madeira, em comparação com a fertilização mineral.

O objetivo deste trabalho foi avaliar o efeito do nitrogênio e do lodo de esgoto compostado nos parâmetros produtivos do trigo.

\section{MATERIAL E MÉTODOS}

O experimento foi conduzido na Fazenda Experimental São Manuel, pertencente à Faculdade de Ciências Agronômicas da UNESP de Botucatu, localizada no município de São Manuel, a 22 25' Latitude Sul, 48 $34^{\prime}$ Longitude Oeste, com altitude de 750 metros.

Foi adotado o delineamento experimental em blocos casualizados, constituídos por 6 tratamentos e 5 repetições assim definidos (PIMENTEL, 2000): TO - sem adubação nitrogenada; T1 - adubação mineral nitrogenada de acordo com Raij et al. (1997); T2 $50 \%$ adubação nitrogenada proveniente do lodo de esgoto e $50 \%$ na forma mineral; T3 - 100\% adubação nitrogenada proveniente do lodo de esgoto; T4 - 150\% adubação nitrogenada proveniente do lodo de esgoto; T5 - 200\% adubação nitrogenada proveniente do lodo de esgoto.

Este ensaio com trigo foi a sexta cultura que esta sendo trabalhada na mesma área do experimento. As culturas trabalhadas foram girassol, aveia, feijão e triticale, sendo que o girassol foram 3 cultivos. Em todas as culturas foram mantidos os mesmos tratamentos.

As parcelas apresentavam as seguintes dimensões $(14 \times 7,2 \mathrm{~m})$ totalizando uma área de $100,8 \mathrm{~m}^{2}$.

Antes da aplicação do composto foi realizada uma roçada no dia 6 de abril de 2009. No dia 14 de abril, foi aplicado o Glyphosate na dose de $1 \mathrm{~L} \mathrm{ha}^{-1}$ do produto comercial que apresentava $480 \mathrm{~g} \mathrm{~L}^{-1}$ do ingrediente ativo glyphosate. No dia 5 de maio foi efetuada outra aplicação de Glyphosate na dose de $2 \mathrm{~L} \mathrm{ha}^{-1} \mathrm{com}$ a mesma concentração de ingrediente ativo aplicado anteriormente.

O composto orgânico utilizado neste ensaio foi feito uma compostagem com lodo de esgoto e bagaço de cana. A metodologia utilizada para a determinação dos nutrientes deste 
composto orgânico foi Lanarv (1988), estas analises foram feitas no Laboratório da Faculdade de Ciências Agrárias da UNESP de Botucatu no Departamento de Recursos Naturais e Ciência do
Solo. As características químicas do composto orgânico utilizado neste ensaio estão apresentadas na Tabela 1.

Tabela 1. Características químicas do composto orgânico utilizado no ensaio.

\begin{tabular}{|c|c|c|c|c|c|c|c|c|c|c|c|c|c|c|c|}
\hline $\mathrm{N}$ & $\mathrm{P}_{2} \mathrm{O}_{5}$ & $\mathrm{~K}_{2} \mathrm{O}$ & Umid. & $\mathrm{MO}$ & C & $\mathrm{Ca}$ & $\mathrm{Mg}$ & $S$ & $\mathrm{Na}$ & $\mathrm{Cu}$ & $\mathrm{Fe}$ & $\mathrm{Mn}$ & $\mathrm{Zn}$ & $\mathrm{C} / \mathrm{N}$ & $\mathrm{pH}$ \\
\hline & & & & $\mathrm{kg}^{-1}$ & & & 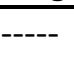 & & & & $m g$ & & & & \\
\hline 2,0 & 1,3 & 0,19 & 51 & 15 & 8,3 & 1,1 & 0,2 & 0,8 & 920 & 84 & 12050 & 270 & 550 & $14 / 1$ & 6,2 \\
\hline
\end{tabular}

As doses empregadas de $\mathrm{N}$ proveniente do composto orgânico nos tratamentos $\mathrm{T} 2, \mathrm{~T} 3, \mathrm{~T} 4$ e T5 foram respectivamente, 32, 64, 96 e $128 \mathrm{~kg}$ $\mathrm{ha}^{-1}$, como o composto orgânico apresenta um teor de $\mathrm{N}$ de $2 \mathrm{~g} \mathrm{~kg}^{-1}$ e considerando a mineralização do $\mathrm{N}$ de 30\% (CONAMA, 2006), com isto tem-se $0,6 \mathrm{~g} \mathrm{~kg}^{-1}$ mineralizado e o teor de umidade de $51 \%$ corresponderia as seguintes doses:10.700, 21.400, 32.099 e $42.798 \mathrm{~kg} \mathrm{ha}^{-1}$ ao natural.

A cultivar utilizada de trigo neste experimento foi a IAC 24. O espaçamento utilizado foi de 0,17 m entrelinhas. A quantidade de sementes utilizadas foi de 68 sementes por $m$ linear que corresponde a $2,5 \mathrm{~g}$ de sementes. $\mathrm{Na}$ adubação de semeadura foi efetuada com $0,77 \mathrm{~kg}$ ha ${ }^{-1}$ de N, $12,36 \mathrm{~kg}$. ha ${ }^{-1}$ de $\mathrm{P}_{2} \mathrm{O}_{5}$ e $21,72 \mathrm{~kg} \mathrm{ha}^{-1}$ de $\mathrm{K}_{2} \mathrm{O}$ para todos os tratamentos.

Após 5 dias da semeadura foi efetuada a adubação nitrogenada no tratamento $\mathrm{T} 1$, na dose de $34,5 \mathrm{~kg} \mathrm{ha}^{-1}$ de $\mathrm{N}$. Aos 35 dias após a semeadura foi adubado com $\mathrm{N}$ nos tratamentos
T1 e T2, na dose de $35 \mathrm{~kg} \mathrm{ha}^{-1}$. A fonte utilizada para a adubação nitrogenada foi a ureia.

Os tratos culturais de plantas daninhas, pragas e doenças foram feitas de acordo com a recomendação para a cultura do trigo.

Neste experimento foram avaliados número de espigas, produtividade de matéria seca e grão, massa de 1.000 grãos e peso hectolitrico $(\mathrm{PH})$.

Os dados de temperatura máxima e mínima no decorrer do desenvolvimento da cultura foram fornecidos pelo Departamento de Recursos Naturais, Área de Ciências Ambientais, da Faculdade de Ciências Agronômicas de Botucatu, na própria Fazenda Experimental São Manuel, onde existe uma estação meteorológica. Para a determinação da precipitação pluviométrica foi instalado na área do experimento um pluviômetro na qual foi coletado os dados todo dia as 9 horas da manha. Os dados de precipitação pluviométrica e temperatura estão representados nas Figuras 1 A e 1 B, respectivamente.

Figura 1. Dados climatológicos no decorrer do experimento. Precipitações pluviométricas, Temperaturas mínimas, médias e máximas.

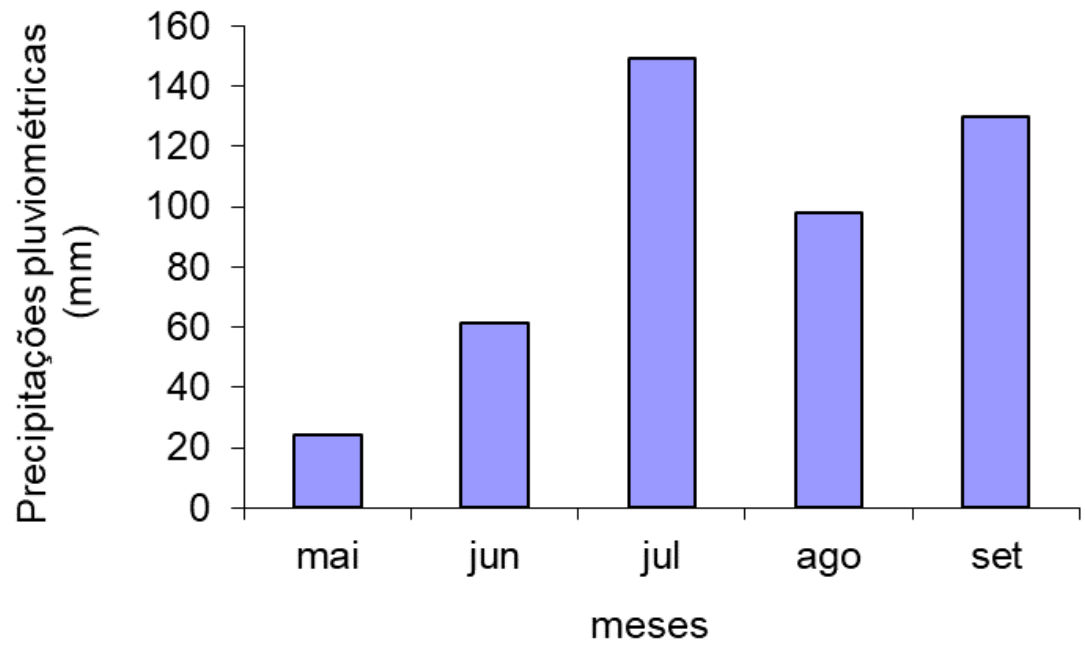




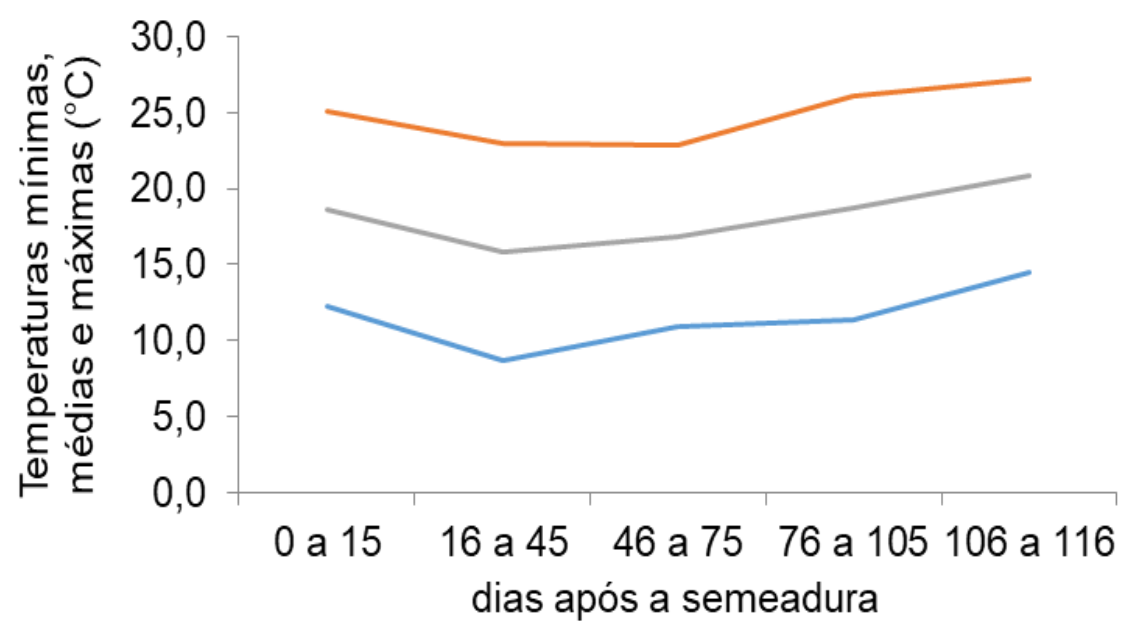

—temp. minima —

Os resultados foram submetidos a análise de variância e as média comparadas pelo teste de Duncan 5\%, para todos os tratamentos empregando o programa de estatística Saeg (1993). Nos tratamentos T0, T3, T4 e T5, nos quais havia aumento da dose de lodo, foi efetuada análise de regressão.

\section{RESULTADOS E DISCUSSÃO}

Observa-se na Tabela 2 que houve variação no numero de espiga final entre os tratamentos, o número de espigas apresentou-se bem superior em relação ao estande inicial da cultura este fator pode ser atribuído ao perfilhamento. $\mathrm{O}$ incremento de $\mathrm{N}$ no solo em doses adequadas proporciona aumento no perfilhamento (MUNDSTOCK; BREDEMEIER, 2002). O perfilhamento é um processo crucial na determinação do rendimento de grãos em trigo, pois está relacionado com a expansão da área foliar durante os estágios iniciais de desenvolvimento e influencia o número de espigas por planta.

Tabela 2. Número de espigas do trigo.em função da dose de lodo e do nitrogênio.

\begin{tabular}{cc}
\hline Tratamentos & No de espigas m \\
\hline Sem N & $274,27 \mathrm{~b}$ \\
$100 \%$ N (uréia) & $428,93 \mathrm{a}$ \\
$50 \%$ N lodo compostado + 50\% N (uréia) & $412,00 \mathrm{a}$ \\
$100 \%$ N composto orgânico & $404,80 \mathrm{a}$ \\
$150 \%$ N composto orgânico & $365,20 \mathrm{a}$ \\
$200 \%$ N composto orgânico & $424,53 \mathrm{a}$ \\
\hline F & 4,70 \\
Média & 384,96 \\
CV & 15,75 \\
\hline
\end{tabular}

Médias seguidas pelas mesmas letras não diferem entre si pelo teste de Duncan 5\% de probabilidade.

O tratamento em que se aplicou $\mathrm{N}$, na forma orgânica ou mineral (T1, T2, T3, T4 e T5), apresentou maior número de espiga que o TO. Entre os tratamentos que foram aplicados $\mathrm{N}$ não diferiu em relação ao tratamento sem $\mathrm{N}$. O lodo de esgoto compostado influenciou positivamente no numero de espiga por $\mathrm{m}^{2}$ para cada tonelada deste resíduo orgânico ocorreu um incremento de 3,19 espigas $\mathrm{m}^{-2}$, sendo que na dose 0 obteve 290 espigas $\mathrm{m}^{-2}$ conforme a equação representada na Figura 2 . 
Figura 2. Número de espigas da cultura do trigo em função da dose de lodo compostado.

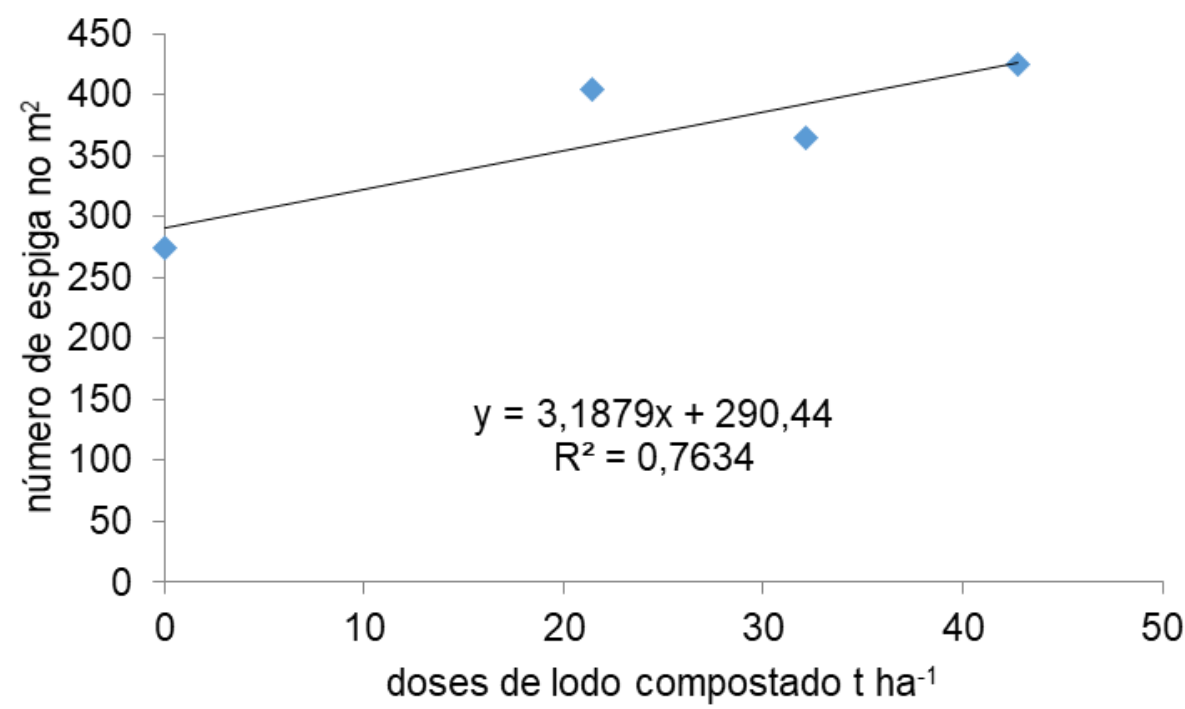

Verifica-se na Tabela 3 que o tratamento que não recebeu $\mathrm{N}, \mathrm{T0}$, apresentou rendimento de matéria seca de trigo inferior a todos os outros tratamentos e a maior dose de lodo (T5) proporcionou maior rendimento de matéria seca. $\mathrm{O}$ aumento da dose de lodo ocorreu incremento linear no rendimento da matéria seca, como se observa na Figura 3.

A diferença de rendimento de matéria seca do T5 em relação ao T0 foi de $2.734 \mathrm{~kg} \mathrm{ha}^{-1}$ de matéria seca, ou seja, superior três vezes a produtividade da testemunha TO. Gargantini et al. (1973) observaram que quando ocorreu excesso de $\mathrm{N}$ no solo, ocorre um maior desenvolvimento vegetativo e paralisação na formação de matéria seca, o que não corrobora com os resultados obtidos neste experimento.

Quanto ao rendimento de grãos (Tabela 3) observa-se que o tratamento $T 5$ foi $o$ tratamento superior a todos os outros tratamentos. O T2 foi superior ao T0, T3 e T4, acredita-se que quando foi aplicado o $\mathrm{N}$ mineral (T2) da mesma maneira que ocorreu em trabalho de Lobo e Grassi Filho (2007). O tratamento T1 obteve um mesmo rendimento de grãos que os tratamentos T2, T3 e T4. O tratamento T0 que não foi feito adubação com $\mathrm{N}$ obteve um rendimento de grãos inferior que os demais tratamentos. O aumento da dose de lodo compostado proporcionou incremento linear no rendimento de grãos (Figura 4). No tratamento em que foi aplicada a maior dose de lodo (T5) a produção foi cerca de 5 vezes maior que o tratamento em que não foi feita aplicação de $\mathrm{N}$ (TO).
Pode-se observar que para a massa de 1000 grãos de trigo o T5 foi superior ao T0, T1, T2 e T3. O T2 foi superior ao T0 e ao T1. O TO foi inferior a todos os tratamentos como se observa na Tabela 3. Teixeira et al. (2007), estudando resposta de 4 cultivares de trigo irrigado por aspersão na região do cerrado a diferentes doses de $N\left(0,30,60,90\right.$ e $\left.120 \mathrm{~kg} \mathrm{ha}^{-1}\right)$, aplicado na forma de ureia em cobertura verificaram que a dose de $\mathrm{N}$ influenciaram na massa de cem grãos. Observa-se na Figura 4 incremento linear na massa de 1000 grãos com o aumento da dose de lodo.

$\mathrm{O}$ PH é um índice referente ao rendimento dos grãos em farinha. Espera-se que amostras com altos valores de $\mathrm{PH}$ apresentem os maiores rendimentos. No entanto, o fato de um genótipo de trigo apresentar maior valor de $\mathrm{PH}$ não assegura que seja de melhor qualidade. Essa relação somente será significativa quando se comparar a mesma variedade com valores de $\mathrm{PH}$ bastante diferenciados, pois muitos fatores são fontes de erros na determinação deste índice, como por exemplo, os espaços vazios entre os grãos, o teor de água e o tipo e a quantidade de impurezas presentes na amostra (MANDARINO, 1993; GUARIENTI, 1996).

De acordo com a norma de identidade e qualidade do trigo (BRASIL, 2001), o PH é utilizado para a classificação em tipos, necessitando, no mínimo, $78 \mathrm{~kg} \mathrm{hL}^{-1}$ para ser considerado tipo 1, para o tipo 2 o valor é de até $75 \mathrm{~kg} \mathrm{hL}^{-1}$ e para o tipo 3 é $70 \mathrm{~kg} \mathrm{hL}^{-1}$. Observa-se na Tabela 3 que os trigos que não foi adubado com $\mathrm{N}, 50 \% \mathrm{~N}$ químico com $50 \% \mathrm{~N}$ mineral e $200 \%$ da recomendação do $\mathrm{N}$ proveniente do 
lodo de esgoto obtiveram um teor de $\mathrm{pH}$ superior que os demais tratamentos. $\mathrm{O}$ aumento da dose de lodo proporcionou um decréscimo no $\mathrm{PH}$ e após a dosagem de $20 \mathrm{t} \mathrm{ha}^{-1}$ ocorreu um acréscimo. Segundo Furlani et al. (2002), uma chuva sobre a lavoura madura reduz $\mathrm{O} \mathrm{PH}$, afetando consequentemente, a qualidade de grão. Neste ensaio ocorreu um excesso de chuva no período de colheita, o que pode ter interferido nos baixos valores obtidos do $\mathrm{PH}$.

Meneghin (2006), Trindade et al. (2006), Frizzone et al. (1996) observaram que a adubação com o aumento da dose de $\mathrm{N}$ houve um decréscimo no $\mathrm{PH}$ do grão do trigo.

Tabela 3. Rendimento de matéria seca, de grão, massa de 1000 grão e Peso hectolitrico do trigo em função do nitrogênio e do lodo de esgoto compostado.

\begin{tabular}{cccccc}
\hline Tratamentos & $\begin{array}{c}\text { M S sem as } \\
\text { esp }\end{array}$ & M S total & $\begin{array}{c}\text { Rendimento } \\
\text { de grão }\end{array}$ & $\begin{array}{c}\text { Massa } \\
\text { de } 1000 \\
\text { grãos } \\
\text { Gramas }\end{array}$ & $\mathrm{PH}$ \\
\hline T0 & $955 \mathrm{c}$ & $1.264 \mathrm{c}$ & $539,97 \mathrm{~d}$ & $26,4 \mathrm{e}$ & $73,6 \mathrm{a}$ \\
T1 & $2.320 \mathrm{~b}$ & $3.043 \mathrm{~b}$ & $1.728,96 \mathrm{bc}$ & $29,2 \mathrm{~d}$ & $70,7 \mathrm{~b}$ \\
T2 & $2.352 \mathrm{~b}$ & $3.142 \mathrm{~b}$ & $2.025,51 \mathrm{~b}$ & $31,8 \mathrm{bc}$ & $75,2 \mathrm{a}$ \\
T3 & $2.281 \mathrm{~b}$ & $3.024 \mathrm{~b}$ & $1.690,06 \mathrm{c}$ & $30,9 \mathrm{~cd}$ & $70,6 \mathrm{~b}$ \\
T4 & $2.012 \mathrm{~b}$ & $2.668 \mathrm{~b}$ & $1.664,67 \mathrm{c}$ & $32,9 \mathrm{ab}$ & $70,6 \mathrm{~b}$ \\
T5 & $3.017 \mathrm{a}$ & $3.999 \mathrm{a}$ & $2.621,71 \mathrm{a}$ & $33,9 \mathrm{a}$ & $74,0 \mathrm{a}$ \\
\hline F & 28,97 & 28,24 & 44,64 & 21,36 & 4,88 \\
Média & 2.156 & 2.857 & $1.711,81$ & 30,08 & 72,44 \\
CV & 13,02 & 13,20 & 13,27 & 4,27 & 2,88 \\
\hline
\end{tabular}

Médias seguidas pelas mesmas letras não diferem entre si pelo teste de Duncan $5 \%$ de probabilidade. T0 - sem N, T1 $-100 \%$ AM, T2 - 50\% AM + 50\% LE, T3 - 100\% LE, T4 - 150\% LE, T5 - 200\% LE. AM - Adubação mineral; LE - Lodo de esgoto. MS- Rendimento de Matéria Seca. Esp - espiga. gr $\mathrm{pl}^{-1}-$ gramas por planta.

Figura 3. Rendimento de matéria seca do trigo em função da dose de lodo compostado.
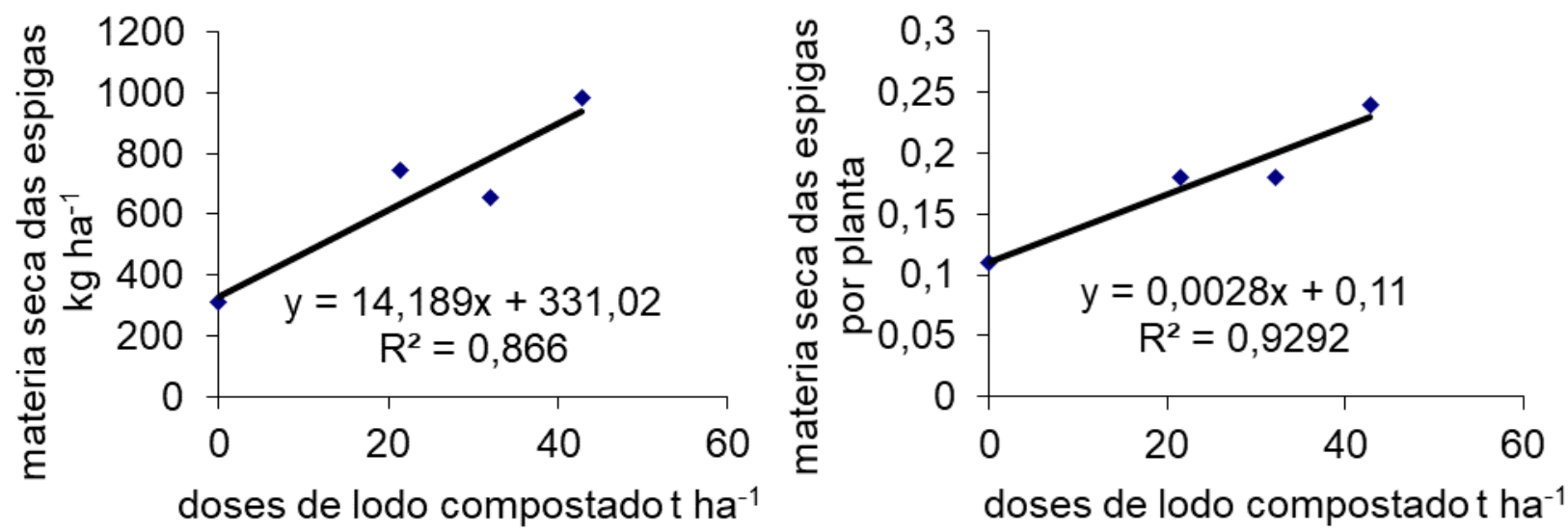

Fonte: elaborada pelos autores. 
Figura 4. Rendimento de grão, Massa de mil sementes e PH do trigo em função da dose de lodo compostado.
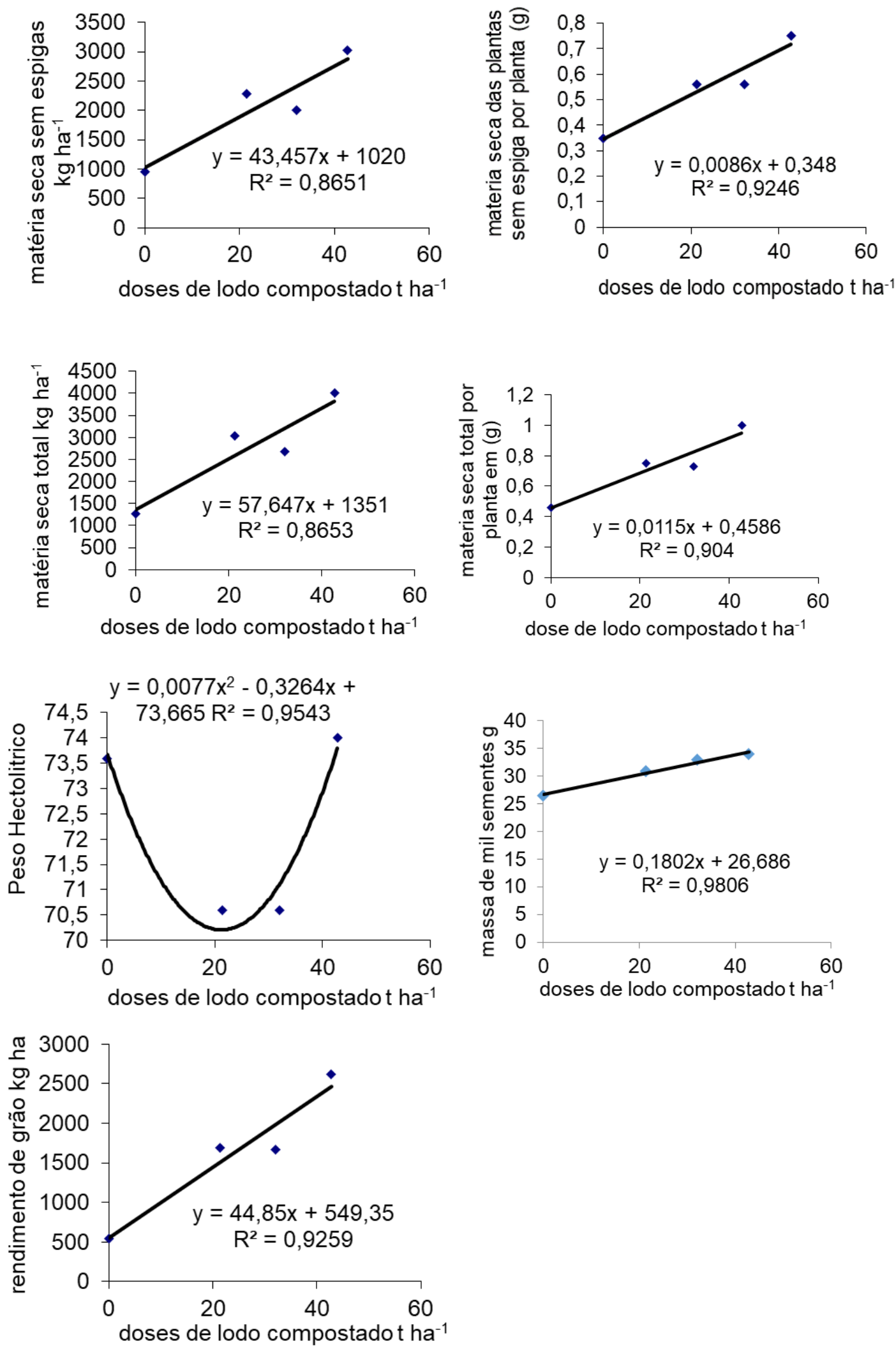

\section{CONCLUSÕES}

A dose de $70 \mathrm{~kg} \mathrm{ha}^{-1}$ de $\mathrm{N}$ no trigo proporcionou um aumento de 155 espigas $\mathrm{m}^{-2}$,
$1.779 \mathrm{~kg} \mathrm{ha}^{-1}$ de matéria seca total, $1.189 \mathrm{~kg} \mathrm{ha}^{-1}$ de produtividade de grãos e 2,8 massa de mil 
sementes em relação ao trigo que não foi adubado com $\mathrm{N}$.

A maior dose de lodo de esgoto testado neste experimento (43 ton ha $\mathrm{h}^{-1}$ ) proporcionaram uma maior produtividade de grãos, matéria seca e massa de mil grãos.

\section{REFERÊNCIAS}

BETIOL, W.; CAMARGO, O.A. Lodo de esgoto na agricultura: potencial de uso e problemas. TEC Hoje, Belo Horizonte, p. 1-4, 2007.

BRASIL. Ministério da Agricultura e Reforma Agrária. Regras para análise de sementes. Brasília: Ministério da Agricultura, 2001.

CHUEIRI, W.A.; SERRAT, B. M.; BIELE, J.; FAVARETTO, N. Lodo de esgoto e fertilizante mineral sobre parametros do solo e das plantas de trigo. Revista Brasileira de Engenharia Agricola e Ambiental, Campina Grande, v. 11, n.5, p. 502508, 2007.

DEFELIPO, B.V.; NOGUEIRA, A.V.; LOUDES, E.G.; ALVARES, Z.V.H. Eficiência agronômica do lodo de esgoto proveniente de uma siderurgia. Revista Brasileira de Ciência do Solo, Campinas, v. 15, n. 3, p. 389-393, 1991.

FRIZZONE, J.A.; MELLO JUNIOR; A.V., FOLEGATTI, M.V.; BOTREL,T.A. Efeito de diferentes níveis de irrigação e adubação nitrogenada sobre componentes de produtividade da cultura do trigo. Pesquisa Agropecuária Brasileira, Brasília, v.31, n.6, p. 425-434, 1996.

FURLANI, A.M.C.; GUERREIRO FILHO, O.; COELHO, R.M.; BETTI,S.A.; FREITAS, S.S. Recomendação da comissão técnica do trigo para 2002. 3. ed. Campinas: Instituto Agronômico, 92p. (Serie tecnologia APTA, Boletim técnico IAC, 167).

GARGANTINI, H.; BLANCO, H.G.; HAAG, H.P.; MALAVOLTA, E. Absorção de Nutrientes pelo trigo. Revista Bragantia, Campinas, v.32 n.16, p. 285-307, 1973. https://doi.org/10.1590/S0006$\underline{87051973000100016}$

GUARIENTI, E. Qualidade industrial do trigo. 2. ed. Passo Fundo: EMBRAPA - CNPT, 1996. 36p.

LAMBAIS, M. R.; DE SOUZA, A.G. Impacto de biossólido nas comunidades microbianas dos solos. In: SEMINÁRIO SOBRE GERENCIAMENTO
DE BIOSSÓLIDO NO MERCOSUL. 2, 1999, Campinas. Anais... Campinas-SP.

LANARV. Análise de corretivos, fertilizantes e inoculantes: métodos oficiais. Brasília: Ministério da Agricultura, 1988. 104p.

LOBO, T. F.; GRASSI FILHO, H.; BULL, L.T. Efeito do nitrogênio e do lodo de esgoto nos fatores produtivos do feijoeiro. Revista Ceres, v. 59, n.1, p. 118-124, 2012.

LOBO, T. F.; GRASSI FILHO, H. Níveis de lodo de esgoto na produtividade do girassol. Journal of Soil Science and Plant Nutrition. Valdivia, v.7, n. 3, p. 16-25, 2007.

MANDARINO, J. M. G. Aspectos importantes para a qualidade do trigo. Londrina: EMBRAPA CNPSo, 1993. 31p.

MENEGHIN, M. F. S. Calibração de nitrogênio para o trigo em solo do distrito federal. 2006. 79f. Dissertação (Mestrado) - Universidade de Brasília, Brasília-DF, 2006.

MUNDSTOCK, C. M.; BREDEMEIER, C. Dinâmica do afilhamento afetada pela disponibilidade de nitrogênio e sua influência na produção de espiga e grãos de trigo. Revista Brasileira Ciência do Solo, Viçosa, v. 26, n. 1, p. 141-149, 2002.

MUNHOZ, R. O. Disponibilidade de fósforo para o milho em solo que recebeu lodo de esgoto. $74 \mathrm{f}$. Dissertação (Mestrado) - Instituto Agronômico de Campinas, Campinas -SP, 2001.

OLIVEIRA, F. C. Disposição de resíduos orgânico e composto de lixo urbano num latossolo vermelho amarelo cultivado com cana-de-açúcar. 2000. 247f. Tese (Doutorado) - Escola Superior de Agricultura Luiz de Queiroz, Piracicaba-SP, 2000.

PEGORINI, E.S.; ANDREOLK,C.V.; SOUZA,M.L; FERREIRA, A. Qualidade do lodo de esgoto utilizado na reciclagem agrícola na região metropolitana de Curitiba - PR. In: simpósio latino americano de biossólido. Anais... São Paulo, jun., 11p, 2003.

PIMENTEL, G. F. Curso de estatística experimental. 14. ed. Piracicaba: Ed. do Autor, 2000. 477p. 
RAIJ, B.V.; CANTARELLA, H.; QUAGGIO, J. A.; FURLANI A. M. C. Recomendações de adubação e calagem para o Estado de São Paulo. 2. ed. Campinas: IAC, 198p. (IAC. Boletim Técnico, 100), 1997.

SABEY, B. R.; AGBIN, N. N.; MARKSTRON, D. C. Land application of sewage sludge. Journal Environmental of Quality, Madison, v.6, n. 1, p.52-58, 1977. https://doi.org/10.2134/jeq1977.6152

SAEG. Sistema para análise estatística. Viçosa: UFV, Fundação Arthur Bernardes, 1993.

TEIXEIRA, F. M.C.M.; BUZETTI, S.; ALVAREZ, R.C.F.; FREITAS, J.G.; ARF, O.; AS, M.E. Resposta de cultivares de trigo irrigado por aspersão ao nitrogênio em cobertura na região do cerrado. Acta Scienthiarum Agronomy, Maringá, v. 29, n. 3, p. 421-425, 2007.

TRINDADE, M. G.; STONE, L. F.; HEINEMANN, A. B.; CÁNOVAS, A. D.; MOREIRA, J. A. A. Nitrogênio e água como fatores de produtividade de trigo no cerrado. Revista Brasileira de Engenharia Agrícola e Ambiental, Campina Grande, v. 10, n. 1, p. 2429, 2006. https://doi.org/10.1590/S1415$\underline{43662006000100004}$

Recebido para publicação em 28/07/2016

Revisado em 25/07/2017

Aceito em 024/03/2018 